\title{
Sarah Nietner
}

\section{Internationaler Entscheidungseinklang im europäischen Kollisionsrecht}

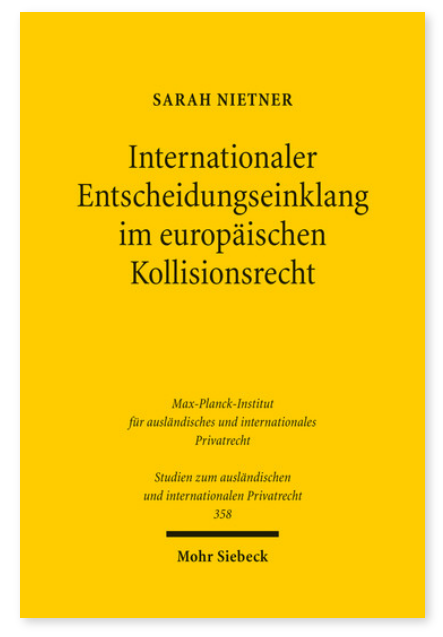

2016. XXVII, 366 Seiten. StudIPR 358

ISBN 978-3-16-154342-5

eBook PDF 79,00€

ISBN 978-3-16-154341-8

fadengeheftete Broschur 79,00€
Das Prinzip des internationalen Entscheidungseinklangs gilt als Leitidee des deutschen Kollisionsrechts und beschreibt die Unabhängigkeit des Ergebnisses eines Rechtsstreits vom Ort des Forums. Nachdem der europäische Gesetzgeber nunmehr nicht nur im internationalen Vermögensrecht, sondern auch im Familien- und Erbrecht tätig geworden ist, steigt das Bedürfnis nach der Transportfähigkeit eines Status und der Vermeidung hinkender Rechtsverhältnisse. Sarah Nietner untersucht, welchen Stellenwert das europäische Kollisionsrecht dem internationalen Entscheidungseinklang in Drittstaatensachverhalten beimisst. Sie behandelt mit Renvoi, Mehrrechtsordnungen, Vorfragen, Eingriffsnormen und der Durchbrechung des Gesamtstatuts durch ein vorrangiges Einzelstatut die allgemeinen Rechtsfiguren des Kollisionsrechts und unterbreitet Normvorschläge für einen allgemeinen Teil des europäischen Internationalen Privatrechts.

Sarah Nietner Geboren 1987; Studium der Rechtswissenschaft, Bucerius Law School Hamburg sowie Stanford Law School (USA); wissenschaftliche Mitarbeiterin am Lehrstuhl für Bürgerliches Recht, Internationales Privat- und Handelsrecht und Rechtsvergleichung, Bucerius Law School Hamburg; seit 2014 Referendarin am OLG Hamburg.

\section{Jetzt bestellen:}

https://mohrsiebeck.com/buch/internationaler-entscheidungseinklang-im-europaeischen-kollisionsrecht-9783161543425? no_cache $=1$

order@mohrsiebeck.com

Telefon: +49 (0)7071-923-17

Telefax: $+49(0) 7071-51104$ 